\title{
Clinical Outcomes among Hemodialysis Patients with Atrial Fibrillation: A Korean Nationwide Population-based Study
}

\section{Yeunmi Kang}

Ewha Women's University Mokdong Hospital

\section{Hyung Yun Choi}

The Korean society of nephrology

\section{Young Eun Kwon}

Hanyang University College of Medicine

Ji Hyeon Shin

Health Insurance Review and Assessment Service

\section{Eun Mi Won}

Health Insurance Review and Assessment Service

\section{Ki Hwa Yang}

Health Insurance Review and Assessment Service

\section{Hyung Jung Oh}

Ewha Women's University Mokdong Hospital

\section{Dong-Ryeol Ryu ( $\nabla$ drryu@ewha.ac.kr)}

Ewha Womans University https://orcid.org/0000-0002-5309-7606

\section{Research article}

Keywords: atrial fibrillation, hemodialysis, hemorrhagic stroke, hospitalization, ischemic stroke, mortality, warfarin

Posted Date: December 30th, 2019

DOl: https://doi.org/10.21203/rs.2.19647/v1

License: (c) (i) This work is licensed under a Creative Commons Attribution 4.0 International License. Read Full License 


\section{Abstract}

Background: The number of patients requiring dialysis is increasing worldwide, and the atrial fibrillation (AF) prevalence among hemodialysis (HD) patients is higher than in the general population. There have been no studies of Korean AF patients undergoing HD investigating how AF affects outcomes, for example, in terms of all-cause mortality, hospitalization, and stroke events. We conducted a large-scale retrospective cohort study with data from the National Health Insurance System (NHIS) to determine how AF affects these outcomes.

Methods: In 2013, the Health Insurance Review and Assessment (HIRA) service, a Korean national health insurance scheme, collected data from 21,839 HD patients for evaluating the adequacy of dialysis centers. All-cause mortality, hospitalization, and stroke events were compared between patients with and without AF. Sub-analyses compared these outcomes between patients receiving and not receiving warfarin.

Results: Cox regression analysis found that $\mathrm{AF}$ was a significant risk factor for death from any cause (HR, 1.356; 95\% Cl, 1.222-1.506, $\mathrm{P}<0.001)$, hospitalization ( $\mathrm{HR}, 1.323 ; 95 \% \mathrm{Cl}, 1.225-1.430, \mathrm{P}<0.001)$, and hemorrhagic stroke $(\mathrm{HR}, 1.500 ; 95 \% \mathrm{Cl}, 1.050-2.141, \mathrm{P}=0.026)$. AF was not significantly associated with an increased risk of ischemic stroke. The use of warfarin was significantly associated with hemorrhagic stroke incidence $(\mathrm{HR}, 1.593 ; 95 \% \mathrm{Cl}, 1.075-2.360, \mathrm{P}=0.020)$, while there was no significant correlation between warfarin treatment and all-cause mortality, hospitalization, and ischemic stroke.

Conclusions: This cohort study of Korean dialysis patients showed that AF was a risk factor for multiple outcomes among HD patients.

\section{Introduction}

Atrial fibrillation (AF) is the most common arrhythmia in the general population, and its prevalence among end-stage renal disease (ESRD) patients undergoing hemodialysis (HD) is higher (ranges from $3.8 \sim 27 \%$ ) [1] than that in general population (ranges from 2.5 3.5\%) [2,3].

Moreover, the incidence of AF increases with age and dialysis duration among chronic HD patients [4]. Furthermore, AF commonly arises secondarily to comorbid conditions, such as coronary artery disease, pericarditis, mitral valve disease, cardiomyopathy, and hemodialysis itself, causing fluid swings leading to heart failure and left atrial dilatation $[5,6]$. Thus, the occurrence of AF among chronic HD patients may carry a poor prognosis [7]. Unfortunately, to our knowledge, there have been no studies investigating the impact of AF on adverse clinical outcomes among Korean chronic HD patients.

Since $A F$ is well-known as a major cause of ischemic stroke in the general population, most physicians consider prescribing anticoagulants for patients at high risk of ischemic stroke. Likewise, among AF patients in the general population, anticoagulant therapy, usually with warfarin, has been used to prevent ischemic stroke among chronic HD patients. However, warfarin should be taken with caution because it 
can increase bleeding tendency. Additionally, chronic HD patients require special care when taking warfarin because they are more likely to be at risk of bleeding. Thus, routine warfarin administration for chronic HD patients is not considered standard treatment. Moreover, it is doubtful that AF in chronic HD patients increases the risk of stroke compared with AF in the general population. Therefore, Kidney Disease: Improving Global Outcomes (KDIGO) guidelines do not advise AF patients to take anticoagulation agents routinely to prevent ischemic stroke when they are undergoing chronic HD [8]. In contrast, the American Heart Association/American College of Cardiology/Heart Rhythm Society (AHA/ACC/HRS) recommends warfarin administration for the HD population to be similar to that for the general population [9].

This study aimed to investigate the impact of AF (AF vs. non-AF) on adverse clinical outcomes (all-cause mortality, hospitalization, and ischemic or hemorrhagic stroke) among a large population of maintenance HD patients in Korea. Moreover, we tried to examine the effects of warfarin (warfarin user vs. warfarin non-user) on clinical outcomes among AF patients undergoing chronic HD.

\section{Subjects And Methods}

\section{Study Population and Data Collection}

The National Health Insurance (NHI) system in Korea is a single-payer system to which $98 \%$ of citizens belong. Under this system, medical providers request reimbursements from the $\mathrm{NHI}$ system. This nationwide cohort study relied on data from the Korean Health Insurance Review and Assessment (HIRA). We used the claim data from between January in 2013 and December in 2017. Among members of the general population who used medical services during the period, we chose patients who were undergoing chronic HD. Moreover, there is a regular national assessment for dialysis adequacy in Korean hospitals where HD has been performed, and we enrolled the patients $(N=21,839)$ who were assessed for dialysis adequacy in 2013. We chose these data because the follow-up duration of patients of the 2013 adequacy assessment was longer than that of the 2015 adequacy assessment. Baseline data, including demographics, comorbid diseases, and laboratory data were collected at the time of patient enrollment.

Additionally, the current study was performed in accordance with the Declaration of Helsinki and approved by the Institutional Review Board (IRB) of Ewha Womans University, Mokdong Hospital (EUMC 2018-12-25). As the study subjects were deidentified, the IRB waived the need for written consents from the patients.

\section{Definitions}

AF was defined when patients were diagnosed with 148 according to the International Classification of Disease, $10^{\text {th }}$ Revision (ICD-10). Moreover, all-cause mortality was regarded as death if a person was extracted from enrollment in the HIRA during the follow-up period, and 'Hospitalization' was considered when a patient had been hospitalized at least once during the follow-up period. 
An ischemic stroke event was recognized when a subject was hospitalized with 163-, 165-, or 166-, and a hemorrhagic stroke event was identified when a patient had been hospitalized with 160.-, 161.- or I62.during the follow-up period.

Warfarin users were defined as those who had $>90$ days of cumulative prescriptions of warfarin. And, hypertension or diabetes mellitus (DM) were defined when patients had a history of using antihypertensive or antidiabetic medications for $>90$ days. Additionally, comorbid diseases were identified from the list of ICD-10 codes.

\section{Outcomes}

Primary outcomes were determined when all-cause mortality, hospitalization, and stroke events occurred.

\section{Statistical Analysis}

We first stratified the total enrolled HD patients into two groups based on the existence of AF (AF vs. nonAF) to investigate the impact of AF on clinical outcomes. Next, we chose the patients with AF and classified these patients into two groups based on the use of warfarin (warfarin user vs. warfarin nonuser) to examine the effect of warfarin use on clinical outcomes among AF patients undergoing HD.

For comparing baseline characteristics, chi-square tests for categorical variables and unpaired t-tests for continuous variables were performed. Continuous variables were expressed as means and standard deviations, and categorical variables were described using frequencies and percentages. Cox proportional hazard modeling was used to explore the association between AF and the incidence of outcomes-allcause mortality, hospitalization, and stroke events (ischemic or hemorrhagic). Moreover, as the Charlson Comorbidity Index (CCl) includes common comorbidities, we used it to adjust for potentially confounding variables. Additionally, same Cox proportional hazard models were conducted to reveal the impact of warfarin on the occurrence of adverse clinical outcomes.

All statistical tests were evaluated using a 2-tailed 95\% confidence interval ( $\mathrm{Cl}$ ) with hazard ratios (HRs). Age, sex, body mass index (BMI), systolic blood pressure (SBP), diastolic blood pressure (DBP), and CCI were used for the adjusted variables. All analyses were performed using SAS, version 9.4 (SAS Institute, Cary, NC, USA), and $\mathrm{P}<0.05$ was considered statically significant.

\section{Results}

\section{Baseline Characteristics}

Table 1 shows the baseline characteristics among enrolled patients. Among the total of 21,839 patients, the mean age was $59.3 \pm 13.0$ years; $12,766(58.5 \%)$ were men; the dialysis vintage was $5.6 \pm 5.1$ years; 
mean BMI was $22.2 \pm 3.3 \mathrm{~kg} / \mathrm{m}^{2}$; and mean SBP and DBP were $141.2 \pm 15.9$ and $78.8 \pm 15.9 \mathrm{mmHg}$, respectively. There were 724 (3.3\%) patients identified with AF (Table 1).

The patients with AF were significantly older, more likely male, had been undergoing HD for longer, and had higher mean SBP and DBP than those without AF.

There were also significantly more several comorbid diseases, such as hypertension, acute myocardial infarction, chronic heart failure, cerebrovascular disease, chronic pulmonary disease, and peptic ulcer in the AF group compared with the non-AF group, while there was no significant difference in urea reduction ratio or the prevalence of DM (Table 1).

\section{Effects of AF on Hemodialysis Patients: All-cause Mortality, Hospitalization, Stroke Events}

Multivariate Cox proportional regression analysis showed that $\mathrm{AF}$ was a significant risk factor for allcause mortality (HR, 1.356; $95 \% \mathrm{Cl}, 1.222-1.506, \mathrm{P}<0.001)$, hospitalization (HR, 1.323; 95\% Cl, $1.225-$ $1.430, \mathrm{P}<0.001)$, and hemorrhagic stroke $(\mathrm{HR}, 1.500 ; 95 \% \mathrm{Cl}, 1.050-2.141, \mathrm{P}=0.026)$, even after adjusting for age, sex, BMI, SBP, DBP, and CCI. AF was not significantly associated with an increased risk of ischemic stroke $(\mathrm{HR}, 1.240 ; 95 \% \mathrm{Cl}, 0.961-1.601, \mathrm{P}=0.984)$ (Table 2). The univariate Cox proportional regression analysis findings are presented in Supplementary Table 1.

\section{Effects of Warfarin Treatment on AF Patients Undergoing Hemodialysis}

We tried to explore the impact of warfarin use on clinical outcomes (all-cause mortality, hospitalization, and ischemic or hemorrhagic stroke) among AF patients undergoing HD, and we investigated their baseline characteristics (Supplementary Table 2). Among 724 total AF patients, there were $177(24.4 \%)$ warfarin users. In the comparisons between the two groups (warfarin users vs. warfarin non-users), we found that mean SBP $(133.7 \pm 14.6$ vs. $139.4 \pm 15.4 \mathrm{mmHg})$ and DBP $(75.6 \pm 10.2$ vs. $77.4 \pm 9.1 \mathrm{mmHg})$ were significantly lower among warfarin users than among non-users. Moreover, serum albumin and creatinine levels were also significantly lower among warfarin users compared with non-users. However, there were significantly more cases congestive heart failure, cerebrovascular disease, DM, and stroke among warfarin users than among non-users (Supplementary Table 2).

When we performed multivariate Cox proportional regression analysis to investigate the impact of warfarin treatment, use of warfarin was significantly associated with increased hemorrhagic stroke incidence $(\mathrm{HR}, 1.593 ; 95 \% \mathrm{Cl}, 1.075-2.360, \mathrm{P}=0.020)$ relative to non-use, while there was no significant association between warfarin treatment and all-cause mortality, hospitalization, and ischemic stroke (Table 3). 


\section{Discussion}

We investigated whether AF would be associated with a worse prognosis among hemodialysis patients using a large-scale, nationwide, population-based database. We noted that AF while undergoing HD was significantly associated with all-cause mortality, hospitalization, and hemorrhagic stroke, but not with ischemic stroke. Moreover, we found that hemorrhagic stroke was more likely to occur among warfarin users among the AF patients undergoing HD compared with non-users, whereas warfarin treatment did not reduce or increase the risk of all-cause mortality, hospitalization, or ischemic stroke.

Several previous studies have demonstrated that AF patients on maintenance dialysis have a poor prognosis. In the RAKUEN study, which was a single-center, retrospective, observational study over a mean period of 36 months, AF was independently associated with death from any cause (HR $1.69,95 \% \mathrm{Cl}$ $1.04-2.74, p=0.034)$, but not significantly associated with ischemic stroke or major bleeding events. Moreover, the findings suggested that AF had less impact on the risk of ischemic stroke in nonanticoagulated patients [10]. In a prospective study conducted by a Japanese group, the authors concluded that patients who had AF at the time of dialysis initiation showed high rates of mortality and cardiovascular or cerebrovascular disease [11]. The potential biologic mechanisms by which AF might cause death include thromboembolic events and worsening of heart failure (induced by tachycardia, or possibly by beat-to beat ventricular irregularity), although the absolute risk increase for heart failure was the highest among the outcomes, such as cardiovascular disease, renal disease, and stroke [12,13]. Data from a study conducted by Genovesi $S$ et al. indicated that left atrial remodeling-because of the presence of heart diseases-is likely to be accelerated by dialytic therapy and has an independent role in increasing the mortality rate [7]. In concordance with these studies, we found that AF was significantly associated with an increased risk of death from any cause. However, we also found increased rates of hospitalization and hemorrhagic stroke in the AF group compared with the non-AF group. We could not determine why hemorrhagic stroke occurred more commonly among AF patients than among those without AF, which was unlike the RAKUEN study. Thus, we investigated whether warfarin use would have an effect hemorrhagic stroke incidence.

We finally revealed that warfarin use was significantly associated with an increased risk of hemorrhagic stroke among the AF patients undergoing HD. The use of anticoagulation therapy for HD patients with AF is still controversial. In a retrospective cohort study, Brandon Kai et al. concluded that warfarin use was associated with lower all-cause mortality and ischemic stroke, without significantly increasing the risk of bleeding in hemodialysis patients with AF [14]. However, another study group demonstrated a significant association between warfarin use and decreased risk of ischemic stroke but no association between warfarin use and death, hemorrhagic stroke, or gastrointestinal bleeding in intention-to-treat analyses (HR, $0.68 ; 95 \% \mathrm{Cl}, 0.47-0.99)$. In contrast, in their as-treated analyses, warfarin use had an association with reduced mortality $(\mathrm{HR}, 0.84 ; 95 \% \mathrm{Cl}, 0.73-0.97)$ [15].

Some studies have generated contrasting findings from the above. In a prospective cohort study of Japanese HD patients with chronic sustained AF, warfarin use did not significantly reduce ischemic 
stroke events [16]. Moreover, in a meta-analysis done by Meng Lee et al., which comprised eight studies, with a total of 9,539 participants and 706 stroke events, warfarin use had a neutral effect on ischemic stroke or thromboembolism incidence among AF patients undergoing hemodialysis. They also indicated that warfarin use was associated with a higher risk of hemorrhagic stroke and bleeding and was associated with no effect on death [17].

The 2019 AHA/ACC/HRS guideline recommends that it might be reasonable to prescribe warfarin (INR 2.0 to 3.0) or apixaban for oral anticoagulation to patients with AF who have a $\mathrm{CHA}_{2} \mathrm{DS}_{2}$-VASc score of 2 or greater in men or 3 or greater in women and those who have end-stage chronic kidney disease (CKD; creatinine clearance $[\mathrm{CrCl}]<15 \mathrm{~mL} / \mathrm{min}$ ) or are on dialysis (Class of Recommendation Ilb, Level of Evidence B-NR) [8]. In a large United States claims database analysis evaluating patients with AF and stage 4 or 5 CKD or undergoing hemolysis, rivaroxaban appeared to be associated with less major bleeding compared with warfarin in patients with severe kidney dysfunction (HR 0.68; 95\% Cl, 0.47-0.99) [18]. In 2018, Siontis et al. published a study comparing apixaban to warfarin among patients with nonvalvular AF undergoing hemodialysis. No difference in the hazard of stroke or systemic embolism was revealed; however, apixaban was associated with a significantly lower risk of major bleeding (HR $0.7295 \% \mathrm{Cl}, 0.59-0.84 ; \mathrm{P}<0.001)$ [19]. Taken together, non-vitamin $\mathrm{K}$ oral anticoagulant, so called NOAC could possibly replace warfarin to lower the risk of bleeding.

This study had some limitations. In our cohort data, the percentage of AF patients was only 3.3\%. Underdiagnosis, missed diagnoses, and code input errors may have contributed to this low prevalence. Because the purpose of adequacy assessment is to qualify dialysis facilities themselves and acquire certification, there is some possibility of selection bias in favor of, for example, outpatients only or excluding patients with severe conditions. Also, not all of the dialysis facilities in Korea were involved in the evaluation. The HAS-BLED score, which evaluates major bleeding risk among anticoagulation patients, was not collected or adjusted.

The strength of this study is that, as HIRA is a national system, our study included a large pool of subjects. Furthermore, the follow-up duration was longer than other previous studies. Additionally, as this study targeted only Korean patients, we generated novel data for this particular ethnic group, which can be used to compare with other groups.

In conclusion, as shown in our analysis, AF could be an independent risk factor for adverse clinical outcomes among HD patients. However, warfarin administration did not decrease the incidence of ischemic stroke, mortality, or hospitalization, rather than it could be associated with an increased risk of hemorrhagic stroke among HD patients. Our study suggests that physicians should specifically assess for $A F$, and they should be more cautious with their $\mathrm{AF}$ patients when they consider prescribing warfarin.

\section{Declarations}

Acknowledgement 
The authors participated in the Joint Project on Quality Assessment Research, and HIRA collected and provided the claims data and quality assessment data to the authors.

\section{Conflicts of interest; None}

\section{List Of Abbreviations}

\# AF: abbreviation of 'atrial fibrillation' is ICD $-10=148$

\# CCl: Charlson Cormorbidity Index

\# CHA2DS2-VASc: congestive heart failure, hypertension, age $\geq 75$ years (doubled), diabetes mellitus, prior stroke or transient ischemic attack or thromboembolism (doubled), vascular disease, age 65 to 74 years, sex category

\# HAS-BLED: Hypertension, Abnormal renal/liver function, Stroke, Bleeding history or predisposition, Labile international normalized ratio, Elderly (>65 years), Drugs/alcohol concomitantly

\section{References}

[1] Königsbrügge $\mathrm{O}$, Posch F, Antlanger $\mathrm{M}$, et al. Prevalence of atrial fibrillation and antithrombotic therapy in hemodialysis patients: cross-sectional results of the Vienna InVestigation of AtriaL Fibrillation and Thromboembolism in Patients on HemoDlaLysis (VIVALDI). PLoS ONE. 2017;12:e0169400.

[2] Ball J, Carrington MJ, McMurray JJV, Stewart S. Atrial fibrillation: profile and burden of an evolving epidemic in the 21st century. Int J Cardiol 2013;167:1807-24.

[3] Saran R, Robinson B, Abbott KC, et al. US Renal Data System 2016 Annual Data Report: epidemiology of kidney disease in the United States. Am J Kidney Dis. 2017;69(3S1):A7-A8.

[4] Goldstein BA, Arce CM, Hlatky MA, Turakhia M, Setoguchi S, Winkelmayer WC. Trends in the incidence of atrial fibrillation in older patients initiating dialysis in the United States. Circulation. 2012;126:22932301.

[5] R. H. Falk. Etiology and complications of atrial fibrillation: insights from pathology studies. Am J Cardiol, 82 (8A) (1998), pp. 10N-17N

[6] Buiten MS, de Bie MK, Rotmans JI, Gabreëls BA, van Dorp W, Wolterbeek R, et al. The dialysis procedure as a trigger for atrial fibrillation: new insights in the development of atrial fibrillation in dialysis patients. Heart. 2014;100:685-90. 
[7] Genovesi S, Vincenti A, Rossi E, Pogliani D, Acquistapace I, Stella A, et al. Atrial fibrillation and morbidity and mortality in a cohort of long-term hemodialysis patients. Am J Kidney Dis. 2008;51:25562.

[8] Herzog CA, Asinger RW, Berger AK, et al. Cardiovascular disease in chronic kidney disease. A clinical update from Kidney Disease: improving Global Outcomes (KDIGO). Kidney Int. 2011;80(6):572-586.

[9] January CT, Wann LS, Calkins H, et al. 2019 AHA/ACC/HRS focused update of the 2014 AHA/ACC/HRS guideline for the management of patients with atrial fibrillation: a report of the American College of Cardiology/American Heart Association Task Force on Clinical Practice Guidelines and the Heart Rhythm. Heart Rhythm. 2019;16(8):e66-e93.

[10] Mitsuma W, Matsubara T, Hatada K, et al. Atrial fibrillation had less impact on the risk of ischemic stroke in non-anticoagulated patients undergoing hemodialysis: insight from the RAKUEN study. Intern Med. 2018;57(16):2295-2300.

[11] Tanaka A, Inaguma D, Shinjo H, et al. Presence of Atrial Fibrillation at the Time of Dialysis Initiation Is Associated with Mortality and Cardiovascular Events. Nephron 2016;132:86-92

[12] Leong DP, Eikelboom JW, Healey JS, Connolly SJ. Atrial fibrillation is associated with increased mortality: causation or association? Eur Heart J. 2013;34(14):1027-1030.

[13] Odutayo A, Wong CX, Hsiao AJ, Hopewell S, Altman DG, Emdin CA. Atrial fibrillation and risks of cardiovascular disease, renal disease, and death: Systematic review and meta-analysis. BMJ. 2016:354i4482.

[14] Kai B, Bogorad Y, Nguyen LN, et al. (2017). Warfarin use and the risk of mortality, stroke, and bleeding in hemodialysis patients with atrial fibrillation. Heart Rhythm 14,645-651.

[15] Shen JI, Montez-Rath ME, Lenihan CR, Turakhia MP, Chang TI, Winkelmayer WC. Outcomes after warfarin initiation in a cohort of hemodialysis patients with newly diagnosed atrial fibrillation. Am J Kidney Dis. 2015;66:677-88.

[16] Wakasugi M, Kazama JJ, Tokumoto A, et al. (2013). Association between warfarin use and incidence of ischemic stroke in Japanese hemodialysis patients with chronic sustained atrial fibrillation: a prospective cohort study. Clin. Exp. Nephrol. 18, 662-669.

[17] Lee M, Saver JL, Hong K-S, et al. Warfarin use and risk of stroke in patients with atrial fibrillation undergoing hemodialysis: a meta-analysis. Medicine. 2016;95(6):e2741

[18] C. I. Coleman, R. Kreutz, N. A. Sood,et al. Rivaroxaban versus warfarin in patients with nonvalvular atrial fibrillation and severe kidney disease or undergoing hemodialysis.

Am J Med 2019 Sep;132(9):1078-1083. 
[19] Siontis KC, Zhang X, Eckard A, et al. Outcomes associated with Apixaban use in end-stage kidney disease patients with atrial fibrillation in the United States. Circulation. 2018;138(15):1519-1529.

\section{Tables}

Table 1. Baseline Characteristics 


\begin{tabular}{|c|c|c|c|c|}
\hline Variables & $\begin{array}{c}\text { All } \\
(\mathrm{N}=21839) \\
\end{array}$ & $\begin{array}{c}\text { Non-AF } \\
(\mathrm{N}=21115) \\
\end{array}$ & $\begin{array}{c}\mathrm{AF} \\
(\mathrm{N}=724)\end{array}$ & $P$-value \\
\hline Age, y & $59.3 \pm 13.0$ & $59.1 \pm 13.0$ & $64.0 \pm 11.0$ & $<0.0001$ \\
\hline Male, \% & $12766(58.5)$ & $12304(58.3)$ & $462(63.8)$ & 0.0029 \\
\hline Dialysis vintage, $\mathrm{y}$ & $5.6 \pm 5.1$ & $5.6 \pm 5.0$ & $6.8 \pm 6.2$ & $<0.0001$ \\
\hline Body mass index, $\mathrm{kg} / \mathrm{m}^{2}$ & $22.2 \pm 3.3$ & $22.2 \pm 3.3$ & $22.1 \pm 3.2$ & 0.5822 \\
\hline SBP (pre-HD), mmHg & $141.2 \pm 15.9$ & $141.3 \pm 15.9$ & $138.1 \pm 15.4$ & $<0.0001$ \\
\hline DBP (pre-HD), mmHg & $78.8 \pm 9.4$ & $78.8 \pm 9.4$ & $76.9 \pm 9.4$ & $<0.0001$ \\
\hline Causes of ESRD & & & & $<0.0001$ \\
\hline DM & $8831(40.4)$ & $8579(40.6)$ & $252(34.8)$ & \\
\hline HTN & $5906(27.0)$ & $5656(26.8)$ & $250(34.5)$ & \\
\hline CGN & 2603 (11.9) & $2535(12.0)$ & $68(9.4)$ & \\
\hline Others & $1859(8.5)$ & $1799(8.5)$ & $60(8.3)$ & \\
\hline Unknown & $2640(12.1)$ & $2546(12.1)$ & $94(13.0)$ & \\
\hline \multicolumn{5}{|l|}{ Laboratory } \\
\hline Hemoglobin, g/dL & $10.6 \pm 0.9$ & $10.6 \pm 0.9$ & $10.7 \pm 0.9$ & 0.1284 \\
\hline Albumin, g/dL & $4.0 \pm 0.3$ & $4.0 \pm 0.3$ & $3.9 \pm 0.3$ & 0.0003 \\
\hline Creatinine, $\mathrm{mg} / \mathrm{dL}$ & $9.7 \pm 2.8$ & $9.7 \pm 2.7$ & $9.2 \pm 2.6$ & $<0.0001$ \\
\hline Total calcium, mg/dL & $9.0 \pm 0.9$ & $9.0 \pm 0.9$ & $9.0 \pm 0.8$ & 0.2203 \\
\hline Phosphorus, mg/dL & $5.1 \pm 1.4$ & $5.1 \pm 1.4$ & $4.9 \pm 1.3$ & 0.0005 \\
\hline Urea reduction ratio, \% & $70.7 \pm 6.0$ & $70.8 \pm 6.0$ & $70.5 \pm 5.7$ & 0.1998 \\
\hline \multicolumn{5}{|l|}{ Comorbidities } \\
\hline Acute MI & $410(1.9)$ & $377(1.8)$ & $33(4.6)$ & $<0.0001$ \\
\hline CHF & $995(4.6)$ & $886(4.2)$ & $109(15.1)$ & $<0.0001$ \\
\hline PVD & $983(6.8)$ & $942(4.5)$ & $41(5.7)$ & 0.125 \\
\hline Cerebrovascular disease & $1485(6.8)$ & $1400(6.6)$ & 85 (11.7) & $<0.0001$ \\
\hline Dementia & 649 (3.0) & $627(3.0)$ & $22(3.0)$ & 0.9141 \\
\hline Chronic pulmonary disease & $1414(6.5)$ & $1354(6.4)$ & $60(8.3)$ & 0.0438 \\
\hline Connective tissue disease & $498(2.3)$ & $481(2.3)$ & $17(2.4)$ & 0.9012 \\
\hline Peptic ulcer & $2425(11.1)$ & $2321(11.0)$ & $104(14.4)$ & 0.0045 \\
\hline Mild liver disease & $1169(5.4)$ & $1134(5.4)$ & $35(4.8)$ & 0.5284 \\
\hline Severe liver disease & $362(1.7)$ & $342(1.6)$ & $20(2.8)$ & 0.0179 \\
\hline DM without complication & $5232(24.0)$ & $5042(23.9)$ & $190(26.2)$ & 0.1428 \\
\hline DM with complication & $7690(35.2)$ & $7442(35.3)$ & $248(34.3)$ & 0.5831 \\
\hline Hemiparesis & $163(0.8)$ & $155(0.7)$ & $8(1.1)$ & 0.2542 \\
\hline Chronic renal disease & $21835(100)$ & $21115(100)$ & $724(100)$ & 0.7111 \\
\hline Cancer without metastasis & $1253(5.7)$ & $1206(5.7)$ & $47(6.5)$ & 0.3748 \\
\hline Cancer with metastasis & $48(0.2)$ & $46(0.2)$ & $2(0.3)$ & 0.6736 \\
\hline AIDS & $1(0)$ & $1(0)$ & $0(0)$ & 1 \\
\hline HTN & $11594(53.1)$ & $11142(52.8)$ & $452(62.4)$ & $<0.0001$ \\
\hline DM & $9649(44.2)$ & $9329(44.2)$ & $320(44.2)$ & 0.9928 \\
\hline Ischemic heart disease & 3163 (14.5) & $2922(13.8)$ & $241(33.3)$ & $<0.0001$ \\
\hline Stroke & $1258(5.8)$ & $1186(5.6)$ & $73(9.9)$ & $<0.0001$ \\
\hline Cancer & $1257(5.8)$ & $1210(5.7)$ & $47(6.5)$ & 0.3872 \\
\hline $\mathrm{AF}$ & $724(3.3)$ & & & \\
\hline
\end{tabular}

Data are expressed as mean \pm standard deviation or $\mathrm{n}(\%)$. 
Abbreviations; AF, atrial fibrillation; SBP, systolic blood pressure; DBP, diastolic blood pressure; HD, hemodialysis; ESRD, end-stage renal disease; DM, diabetes mellitus; HTN, hypertension; CGN, chronic glomerulonephritis; MI, myocardial infarction; CHF, congestive heart failure; PVD, peripheral vascular disease; AIDS, acquired immunodeficiency syndrome

Table 2. Multivariate Cox Analysis for All-cause Mortality, Hospitalization and Stroke events

\begin{tabular}{|c|c|c|c|c|c|c|c|c|}
\hline \multirow[t]{3}{*}{ Variables } & \multicolumn{8}{|c|}{ Multivariate Analysis } \\
\hline & \multicolumn{2}{|c|}{$\begin{array}{l}\text { All-cause } \\
\text { Mortality }\end{array}$} & \multicolumn{2}{|c|}{ Hospitalization } & \multicolumn{2}{|c|}{ Ischemic stroke } & \multicolumn{2}{|c|}{$\begin{array}{c}\text { Hemorrhagic } \\
\text { stroke }\end{array}$} \\
\hline & $\begin{array}{l}\mathrm{HR} \\
(95 \% \\
\mathrm{CI})\end{array}$ & $P$-value & $\begin{array}{l}\mathrm{HR} \\
(95 \% \\
\mathrm{CI})\end{array}$ & $P$-value & $\begin{array}{l}\text { HR } \\
(95 \% \\
\text { CI) }\end{array}$ & $P$-value & $\begin{array}{l}\text { HR } \\
(95 \% \\
\text { CI) }\end{array}$ & $P$-value \\
\hline $\begin{array}{l}\text { Age, per 1- } \\
\text { year } \\
\text { increase }\end{array}$ & $\begin{array}{c}1.053 \\
(1.051- \\
1.056)\end{array}$ & $<0.0001$ & $\begin{array}{l}1.013 \\
(1.012- \\
1.014)\end{array}$ & $<0.0001$ & $\begin{array}{l}1.047 \\
(1.042- \\
1.052)\end{array}$ & $<0.0001$ & $\begin{array}{c}1.019 \\
(1.012- \\
1.025)\end{array}$ & $<0.0001$ \\
\hline $\begin{array}{l}\text { Male (vs. } \\
\text { Female) }\end{array}$ & $\begin{array}{c}1.188 \\
(1.133- \\
1.246)\end{array}$ & $<0.0001$ & $\begin{array}{c}0.956 \\
(0.928- \\
0.985)\end{array}$ & 0.0029 & $\begin{array}{c}1.111 \\
(0.999- \\
1.236)\end{array}$ & 0.0522 & $\begin{array}{c}0.892 \\
(0.766- \\
1.037)\end{array}$ & 0.892 \\
\hline $\begin{array}{l}\text { BMI, per 1- } \\
\mathrm{kg} / \mathrm{m}^{2} \\
\text { increase }\end{array}$ & $\begin{array}{c}0.971 \\
(0.963- \\
0.978)\end{array}$ & $<0.0001$ & $\begin{array}{c}1.000 \\
(0.998- \\
1.001)\end{array}$ & 0.4378 & $\begin{array}{c}0.999 \\
(0.993- \\
1.006)\end{array}$ & 0.861 & $\begin{array}{c}0.933 \\
(0.910- \\
0.957)\end{array}$ & $<0.0001$ \\
\hline $\begin{array}{l}\text { SBP (pre- } \\
\text { HD), per 1- } \\
\text { mmHg } \\
\text { increase }\end{array}$ & $\begin{array}{l}1.005 \\
(1.003- \\
1.007)\end{array}$ & $<0.0001$ & $\begin{array}{l}1.004 \\
(1.002- \\
1.005)\end{array}$ & $<0.0001$ & $\begin{array}{l}1.013 \\
(1.009- \\
1.016)\end{array}$ & $<0.0001$ & $\begin{array}{l}1.010 \\
(1.004- \\
1.015)\end{array}$ & 0.0006 \\
\hline $\begin{array}{l}\text { DBP (pre- } \\
\text { HD), per 1- } \\
\text { mmHg } \\
\text { increase }\end{array}$ & $\begin{array}{l}1.000 \\
(0.998- \\
1.003)\end{array}$ & 0.7337 & $\begin{array}{c}0.997 \\
(0.995- \\
0.999)\end{array}$ & 0.0053 & $\begin{array}{c}1.002 \\
(0.996- \\
1.008)\end{array}$ & 0.5695 & $\begin{array}{c}1.019 \\
(1.009- \\
1.029)\end{array}$ & 0.0002 \\
\hline $\begin{array}{l}\text { CCI, per 1- } \\
\text { unit } \\
\text { increase }\end{array}$ & $\begin{array}{l}1.127 \\
(1.113- \\
1.141)\end{array}$ & $<0.0001$ & $\begin{array}{l}1.112 \\
(1.102- \\
1.122)\end{array}$ & $<0.0001$ & $\begin{array}{l}1.136 \\
(1.104- \\
1.169)\end{array}$ & $<0.0001$ & $\begin{array}{l}1.104 \\
(1.056- \\
1.153)\end{array}$ & $<0.0001$ \\
\hline $\begin{array}{l}\text { AF (vs. Non } \\
\text { AF) }\end{array}$ & $\begin{array}{c}1.356 \\
(1.222- \\
1.506) \\
\end{array}$ & $<0.0001$ & $\begin{array}{l}1.323 \\
(1.225- \\
1.430)\end{array}$ & $<0.0001$ & $\begin{array}{c}1.240 \\
(0.961- \\
1.601)\end{array}$ & 0.0984 & $\begin{array}{l}1.500 \\
(1.050- \\
2.142) \\
\end{array}$ & 0.0258 \\
\hline
\end{tabular}

Abbreviations; HR, hazard ratio; CI, confidence interval; BMI, body mass index; SBP, systolic blood pressure; DBP, diastolic blood pressure; HD, hemodialysis; CCI, Charlson Comorbidity Index; AF, atrial fibrillation

*Multivariate Cox analysis was conducted after being adjusted for age, sex, BMI, SBP, DBP, CCI. 
Table 3. Effect of Warfarin Treatment in Hemodialysis Patients with Atrial Fibrillation

\begin{tabular}{|c|c|c|c|c|c|c|c|c|}
\hline & \multicolumn{2}{|c|}{ Mortality } & \multicolumn{2}{|c|}{ Hospitalization } & \multicolumn{2}{|c|}{ Ischemic stroke } & \multicolumn{2}{|c|}{$\begin{array}{l}\text { Hemorrhagic } \\
\text { stroke }\end{array}$} \\
\hline & $\begin{array}{l}\text { HR (95\% } \\
\text { CI) }\end{array}$ & $\begin{array}{c}P- \\
\text { value }\end{array}$ & $\begin{array}{c}\text { HR } \\
(95 \% \mathrm{CI})\end{array}$ & $\begin{array}{c}P- \\
\text { value }\end{array}$ & $\begin{array}{c}\text { HR } \\
(95 \% \\
\text { CI })\end{array}$ & $\begin{array}{c}P- \\
\text { value }\end{array}$ & $\begin{array}{c}\text { HR } \\
(95 \% \\
\text { CI })\end{array}$ & $\begin{array}{c}P- \\
\text { value }\end{array}$ \\
\hline $\begin{array}{c}\text { Univariate } \\
\text { Analysis }\end{array}$ & $\begin{array}{c}1.193 \\
(0.946- \\
1.504)\end{array}$ & 0.137 & $\begin{array}{l}1.158 \\
(0.972- \\
1.381)\end{array}$ & 0.1004 & $\begin{array}{c}1.163 \\
(0.846- \\
1.598)\end{array}$ & 0.353 & $\begin{array}{l}1.632 \\
(1.103- \\
2.415)\end{array}$ & 0.0143 \\
\hline $\begin{array}{c}\text { Multivariate } \\
\text { Analysis* }\end{array}$ & $\begin{array}{c}1.151 \\
(0.908- \\
1.459)\end{array}$ & 0.2464 & $\begin{array}{c}1.14 \\
(0.951- \\
1.367)\end{array}$ & 0.1567 & $\begin{array}{c}0.986 \\
(0.716- \\
1.356)\end{array}$ & 0.9292 & $\begin{array}{c}1.593 \\
(1.075- \\
2.360)\end{array}$ & 0.0203 \\
\hline
\end{tabular}

Abbreviations; HR, hazard ratio; CI, confidence interval

*Multivariate Cox analysis was conducted after being adjusted for age sex, BMI, SBP, DBP, $\mathrm{CCI}, \mathrm{Hb}$.

\section{Supplementary Files}

This is a list of supplementary files associated with this preprint. Click to download.

- SupplementaryTables.docx 